\title{
Contingent negative variation and personality in depression
}

\author{
Michel Hansenne, Marc Ansseau \\ Department of Psychiatry, Centre Hospitalier Universitaire du Sart Tilman (B-35), Liège, Belgium
}

KEYWORDS: contigent negative variation, depression, personality, temperament and character inventory

\begin{abstract}
Contingent negative variation $(\mathrm{CNV})$ has been applied in depression with controversial results. A major source for these controversial results could result from the diversity of depressed patients included in the different studies. Supporting this assumption, impulsivity, blunted affect and suicidal behavior significantly influence CNV amplitude. However, no data are available on the possible influences of personality of depressed patients on CNV. Since personality is related to CNV in normal subjects, the aim of the present study was to investigate the relationship between CNV and personality as assessed by the Temperament and Character Inventory (TCI) in 52 depressed patients. A group of 76 healthy volunteers was included in the study. Among depressed patients, the main results of the study shows that CNV amplitude is positively correlated with self-transcendence dimension. In healthy volunteers, results show that CNV amplitude is negatively correlated with novelty seeking and persistence dimensions. The other dimensions are not related to CNV amplitude either in depressed patients or in healthy volunteers. The findings among depressed subjects suggest that lower CNV amplitude may be associated with psychotic traits (high self-transcendence scores), and those observed in healthy subjects are consistent with previous studies and support energetical models of slow potentials. However, the preliminary nature of the present results with respect to the weak statistical significance should be underlined.
\end{abstract}




\section{Introduction}

Contingent negative variation (CNV) is a surface negative slow potential recorded from human subjects during a fixed foreperiod of a warned reaction time task [1]. This electric phenomenon of the brain has drawn the interest of many psychophysiologists because it is thought to reflect some psychological processes such as expectancy, motivation, arousal, attention, time estimation and motor preparation [2-4]. Several lines of evidence suggest that CNV is constituted of two different components. The first, or early CNV, is related to the orienting response and exhibits a rapid habituation. The second component, or late CNV, has been associated with motor preparation and stimulus anticipation [4-7].

CNV abnormalities have been reported in several psychiatric disorders, especially in dementia, schizophrenia and depression [8]. Concerning depressive disorders, abnormalities in CNV amplitude and duration have been described with some controversies. Whereas some studies have reported that depressed patients exhibited lower CNV amplitude [8-12], other studies have suggested that in depressed patients CNV amplitude was similar to that in healthy controls [1316]. A major source for these controversial results could result, at least in part, from the diversity of depressed patients included in these different studies. Supporting this assumption, impulsivity, blunted affect and suicidal behavior significantly influence CNV amplitude in depression [17-22]. However, no data are available on the possible influences of personality of depressed patients on CNV.

Several studies have reported that CNV was related to many personality dimensions in healthy subjects. Introverts exhibit lower CNV amplitude in a standard paradigm [23], but the relationship between extraversion and CNV amplitude is not linear and presents an interaction with the experimental condition [24]. Moreover, the effects of chlordiazepoxide and caffeine on CNV amplitude correlated significantly with the extraversion score [25]. Social extraversion was associated with greater CNV amplitude within the left hemisphere [26]. Finally, persons scoring high on sensation seeking showed larger CNV amplitude than low scorers on this dimension [27]. According to these authors, this finding is interpreted as suggesting that larger CNV amplitudes reflect emotions that were approach related rather than avoidance related.

Since personality was related to CNV in normal subjects, the aim of the present study was to investigate the relationship between CNV amplitude and the Temperament and Character Inventory (TCI) in depressed subjects. The TCI is a 226-item self-questionnaire developed to assess the seven dimensions of the biosocial model of personality proposed by Cloninger et al. $[28,29]$. This model is based on four temperaments (novelty seeking, harm avoidance, reward dependence, and persistence) and three characters (self-directedness, cooperativeness, and selftranscendence). Novelty seeking is defined as the tendency to respond actively to novel stimuli leading to pursuit of rewards and escape from punishment. Harm avoidance corresponds to the tendency toward an inhibitory response to signals of aversive stimuli that lead to avoidance of punishment and nonreward. Reward dependence is defined as the tendency for a positive response to signals of reward to maintain or resist behavioral extinction. Persistence is described in terms of perseverance despite frustration and fatigue. Self-directedness refers to the ability of an individual to control, regulate and adapt his behavior to fit the situation in 
accord with individually chosen goals and values. Cooperativeness is formulated to account for individual differences in identification with and acceptance of other people. Self-transcendence is a character associated with spirituality, and refers generally to identification with everything conceived as essential and consequential parts of a unified whole.

The model of Cloninger is interesting to study the relationship between CNV and personality because it shares some theoretical constructs with CNV. Indeed, novelty seeking is linked to the behavioral activation system and approach-related behavior. According to the energetical models of slow potentials [30-32], enhanced CNV amplitude represents a higher cerebral potentiality in the anticipation and approach-related tasks, and amplitude variation in CNV is usually considered as a sign of variation in intensity of activation/inhibition of neural structures in the brain by the task variables. Therefore, the aim of the present study was to investigate the relationships between CNV and personality as assessed by the Cloninger model of personality among depressed patients. Since the relationships between CNV and TCI were never performed in normal subjects, a group of healthy volunteers was included in the present study.

\section{Subjects and methods}

\section{SUBJECTS}

The study was conducted in 52 depressive inpatients admitted to the Department of Psychiatry of the University Hospital of Liège (Belgium). The sample comprised 30 men and 22 women with a mean age of 40.7 years ( $S D=11.7)$. All patients met DSM-IV criteria for major depressive disorder [33], with a mean score of $28.1(\mathrm{SD}=6.8)$ on the 17-item Hamilton depression scale [34]. Since suicidal behavior has previously been shown to influence CNV amplitude [20, 21], all patients selected were free from acute and/or past suicide attempts. Clinical examinations assessed that the patients were free of medical illness. A group of 76 experimentally naive healthy subjects (42 women and 34 men, mean age of 35.8 B 11.9 years) recruited among the staff of the University Hospital of Liège (Belgium) was included in the study. They were paid for their participation $(10,000 \mathrm{BEF})$. They all underwent a medical interview to exclude psychiatric or somatic disorders. The Ethical Committee of the University of Liège Medical School approved the protocol and all subjects gave their informed consent.

\section{PERSONALITY ASSESSMENT}

The depressed subjects and the healthy volunteers completed a French version of the 226-item self-questionnaire TCI within the day following the CNV recording. Cloninger has recommended the translated version of the TCI used in the study. It has been performed by Téhérani and Lépine and validated by Pélissolo and Lépine [35]. The patients were asked to read each item carefully and to answer with a pencil all of them even if they are not completely sure of the answer. After the patients have completed the questionnaire, one author (M.H.) checked if all the items of the questionnaire have been completed. All patients have filled in 'false' for the validity item (I have lied a lot in this questionnaire). 
Table 1. Mean and standard deviation of TCI dimension scores among depressed inpatients $(n=52)$ and healthy volunteers $(n=76)$

\begin{tabular}{lcccc}
\hline TCI dimensions & $\begin{array}{c}\text { Depressed } \\
\text { patients }\end{array}$ & Controls & $\begin{array}{c}\text { T value } \\
(\mathrm{df}=126)\end{array}$ & $\mathrm{p}$ \\
\hline Novelty seeking & $16.9 \pm 6.0$ & $19.5 \pm 6.3$ & 2.34 & 0.02 \\
Harm avoidance & $25.2 \pm 5.8$ & $13.3 \pm 5.6$ & -11.54 & $<0.001$ \\
Reward dependence & $14.9 \pm 4.3$ & $15.9 \pm 3.9$ & 1.33 & 0.18 \\
Persistence & $4.1 \pm 2.3$ & $4.1 \pm 2.0$ & 0.05 & 0.95 \\
Self-directedness & $23.4 \pm 8.4$ & $34.1 \pm 6.3$ & 8.18 & $<0.001$ \\
Cooperativeness & $28.4 \pm 5.8$ & $32.3 \pm 4.1$ & 4.47 & $<0.001$ \\
Self-transcendence & $14.1 \pm 6.2$ & $10.0 \pm 5.2$ & -4.03 & $<0.001$ \\
\hline
\end{tabular}

Table 2.Partial correlation coefficients between CNV amplitude and reaction time (RT) and the personality dimensions of the TCI and age among 52 depressed patients

\begin{tabular}{|c|c|c|c|c|c|c|c|c|c|}
\hline & & NS & HA & $\mathrm{RD}$ & $P$ & SD & $\mathrm{CO}$ & ST & Age \\
\hline \multirow[t]{3}{*}{ CNV amplitude } & $\mathrm{Fz}$ & -0.01 & 0.15 & -0.07 & -0.18 & -0.10 & 0.25 & 0.27 & 0.06 \\
\hline & $\mathrm{Cz}$ & -0.03 & 0.14 & -0.03 & -0.09 & -0.07 & 0.04 & $0.34^{*}$ & 0.16 \\
\hline & $\mathrm{Pz}$ & -0.07 & -0.01 & -0.04 & -0.16 & -0.08 & 0.01 & $0.33^{*}$ & 0.12 \\
\hline RT & & 0.16 & 0.29 & 0.08 & 0.10 & 0.02 & -0.08 & 0.02 & 0.31 \\
\hline
\end{tabular}

$\mathrm{NS}$ = Novelty seeking; $\mathrm{HA}=$ harm avoidance; $\mathrm{RD}=$ reward dependence; $\mathrm{P}=$ persistence;

$\mathrm{SD}=$ self-directedness; $\mathrm{CO}=$ cooperativeness; $\mathrm{ST}=$ self-transcendence. ${ }^{*} \mathrm{p}<0.05$.

\section{CNV PROCEDURE, RECORDING AND DATA ANALYSIS}

The CNV paradigm consisted of a warning stimulus (S1, tone of 1,000 Hz, $75 \mathrm{~dB}$, and 50-ms duration) followed $1 \mathrm{~s}$ later by an imperative stimulus ( 2 2, series of $18 \mathrm{~Hz}$ squared light flashes). The subject's task was to interrupt the $\mathrm{S} 2$ by a fast button press with the dominant hand. Trials were automatically excluded if there were button presses within the S1-S2 interval. Intertrial intervals varied randomly from 5 to $10 \mathrm{~s}$. The subjects were asked to relax and to blink as little as possible, and if necessary only after the motor response. Oculomotor artifacts were evaluated by visual inspection of electrooculogram (EOG) tracings. The task duration was approximately $10 \mathrm{~min}$, and few trials (2-7) were rejected due to eye movements or premature presses. The $\mathrm{CNV}$ was determined from an average of 32 artifact-free trials. CNV amplitude was quantified as the mean amplitude during a 200-ms interval prior to S2, referred to a $1 \mathrm{~s}$ before S1 baseline. The EEG was recorded with silver/silver-chloride electrodes from $\mathrm{Fz}, \mathrm{Cz}$, and Pz, referred to linked earlobes. Vertical EOG was recorded via electrodes above and below the left eye. An electrode placed on the right forehead served as ground. All sites were cleaned with acetone and prepared to keep the resistance below $5 \mathrm{k} ø$. All EEG and EOG channels were amplified with a Nihon Kohden electroencephalogram model 7310 with a time constant of $8 \mathrm{~s}$ and a high-cut frequency of $50 \mathrm{~Hz}$. EEG signals were digitized at a rate of $64 \mathrm{~Hz}$. 


\section{STATISTICAL ANALYSIS}

The statistical analyses were carried out using Statistica (4.5) for Windows (Statsoft, 1993, Statsoft, Tulsa, Okla., USA). Rather than selecting groups of subjects that were high or low on dimensions and then analyzing group differences with Anova, in the present study, a large sample of subjects was tested, and the relationships between CNV and TCI data were assessed by correlation coefficients. Since age and severity of depression interact with either CNV measures or TCI scores, partial correlations were computed. Group differences were assessed by Student's t tests.

\section{Results}

Reaction time was delayed in depressed patients: $348 \pm 190.1$ ms versus 225 B 71.2 ms in controls $(t=5.13, p<0.001)$. CNV amplitude was significantly lower in depressed patients as compared to healthy volunteers: $\mathrm{Fz},-11.3 \pm 5.8$ versus $-16.3 \pm 7.9 \mu \mathrm{V}(\mathrm{t}=3.84, \mathrm{p}<0.001) ; \mathrm{Cz}$, $-11.2 \pm 5.6$ versus $-18.6 \pm 6.9 \mu \mathrm{V}(\mathrm{t}=6.40, \mathrm{p}<0.001) ; \mathrm{Pz},-6.4 \pm 5.1$ versus $-11.1 \pm 5.3 \mu \mathrm{V}(\mathrm{t}=$ 4.92, $\mathrm{p}<0.001)$. Mean and standard deviations of the TCI dimensions are represented in table 1. Depressed patients exhibited higher scores on harm avoidance and self-transcendence dimensions and lower scores on novelty seeking, self-directedness and cooperativeness dimensions. Partial correlation coefficients between CNV, TCI scores and age are presented in table 2 for depressed patients and in table 3 for healthy volunteers. Among depressed patients, CNV amplitude was positively correlated with self-transcendence dimension $(r=0.34, p=0.02$ at $\mathrm{Cz} ; \mathrm{r}=0.33, \mathrm{p}=0.02$ at $\mathrm{Pz}$ ). Among healthy volunteers, $\mathrm{CNV}$ amplitude was negatively correlated with both novelty seeking dimension $(r=-0.39, p<0.001$ at Fz; $r=-0.27, p=0.02$ at $\mathrm{Cz}$ ) and persistence dimension $(\mathrm{r}=-0.31, \mathrm{p}<0.01$ at $\mathrm{Cz})$. Age was positively correlated with reaction time $(r=0.45, \mathrm{p}<0.001)$.

Table 3. Partial correlation coefficients between CNV amplitude and reaction time (RT) and the personality dimensions of the TCI and age among 76 healthy subjects

\begin{tabular}{lcccccccccc}
\hline & & NS & HA & RD & P & SD & CO & ST & Age \\
\hline CNV amplitude & $\mathrm{Fz}$ & $-0.39^{*}$ & 0.19 & 0.13 & -0.23 & -0.15 & -0.06 & 0.13 & -0.05 \\
& $\mathrm{Cz}$ & $-0.27^{*}$ & 0.15 & 0.08 & $-0.31^{*}$ & 0.01 & -0.15 & 0.20 & -0.05 \\
& $\mathrm{Pz}$ & -0.20 & 0.13 & -0.01 & -0.21 & -0.02 & -0.08 & 0.17 & -0.20 \\
$\mathrm{RT}$ & & 0.03 & -0.02 & 0.06 & 0.02 & $0.0 *$ & -0.20 & 0.04 & $0.45^{*}$ \\
\hline
\end{tabular}

$\mathrm{NS}=$ Novelty seeking; $\mathrm{HA}=$ harm avoidance; $\mathrm{RD}=$ reward dependence; $\mathrm{P}=$ persistence;

$\mathrm{SD}=$ self-directedness; $\mathrm{CO}=$ cooperativeness; $\mathrm{ST}=$ self-transcendence. ${ }^{*} \mathrm{p}<0.05$. 


\section{Discussion}

In the present study, CNV amplitude is positively correlated with self-transcendence dimension in depressed patients. This indicates that lower CNV amplitude may be associated with higher self-transcendence score. Higher self-transcendence scores when combined with good development on the two other character dimensions (self-directedness and cooperativeness) are associated with mature creativity. However, according to Cloninger, when combined with poor development of one or both of the other character dimensions, higher self-transcendence scores are associated with proneness to psychosis and personality disorders. The results of the present study show that depressed patients exhibited lower self-directedness and lower cooperativeness scores. This TCI profile corresponds to the schizotypical configuration described by Cloninger and Svrakic [36]. Therefore, the association found among depressed patients between CNV amplitude and this dimension may indicate that lower CNV amplitude may be observed more frequently in severely depressed patients with eventual psychotic traits. This assumption is supported by the fact that some studies have reported that CNV amplitude is correlated with the severity of depression [12, 37, 38]. More interestingly, reduced CNV amplitude is observed in schizophrenia [39, 40].

A limitation of the study is that personality has been assessed during the depressive disorder. Indeed, several studies have reported that the personality assessment during a mood disorder is related to the clinical state of the patients, even if they were requested to answer the items of the questionnaires in reference to their normal functioning [41-43]. In fact, the relationship between personality and depression is extremely complex: personality features may predispose an individual to depression; the personality can be modified after a depression; the personality can modify the clinical presentation of a depressive disorder, and finally the personality can be considered like a subclinical manifestation of a depressive disorder [44, 45]. The state dependence of CNV amplitude may also explain the weakness of the correlations between CNV and TCI dimensions. Indeed, several lines of evidence have suggested that CNV amplitude increased after a successful treatment [11-46].

Among healthy volunteers, CNV amplitude is correlated with novelty seeking dimension. This indicates that higher CNV amplitude is associated with higher novelty seeking score. This finding is consistent with energetical models of slow potentials [30-32]. Moreover, this association is consistent with earlier studies on CNV-personality relationships. Indeed, Howard et al. [26] have reported a negative relationship between $\mathrm{CNV}$ amplitude and the subscale social extraversion of the Eysenck's model of personality, and Krijns et al. [27] have demonstrated that CNV amplitude was larger for high than for low sensation seeking subjects. Some authors have suggested that novelty seeking shares many traits with extraversion [47, 48] and sensation seeking [49]. However, McCourt et al. [50] have suggested that novelty seeking is not the same as sensation seeking. The relationship between novelty seeking and CNV amplitude can also be explained by their underlying neurobiological bases. Indeed, novelty seeking is mediated by the mesocortical dopaminergic system. Several studies have confirmed this association $[49,50]$, although other studies have not [51, 52]. On the other hand, many studies have demonstrated that dopaminergic agents modulate CNV amplitude [53-55]. It must be noted, however, that recent 
studies have suggested that magnitude of the CNV bears a non-monotonic 'inverted U' relation to neurotransmitter activity [54].

Finally, the negative relationship between persistence (perseverance) and CNV amplitude among healthy subjects indicates that individuals with a higher score of this dimension are characterized by higher CNV amplitude. The subjects who have a higher score on persistence are described in terms of perseverance despite frustration and fatigue. It is possible that these individuals exhibited higher cortical arousal and as a consequence a higher CNV amplitude. This finding is consistent with the study of Krijns et al. [27] who reported that persons scoring high on the sensation seeking scale exhibited larger CNV amplitudes than low scorers on this dimension, if we admit that sensation seeking could be associated with persistence.

In conclusion, the findings among depressed subjects suggest that a lower CNV amplitude could be associated with psychotic traits (high self-transcendence scores) and those observed in healthy subjects are consistent with previous studies and support energetical models of slow potentials. However, the preliminary nature of the present results with respect to the weak statistical significance (type I error inflation with multiple significance tests) should be underlined. 


\section{References}

1. Walter WG, Cooper R, Aldridge VJ, McCal-um WC, Winter AL: Contingent negative variation, an electrical sign of sensory-motor association and expectancy in the human brain. Nature 1964;203:380-384.

2. Tecce JJ: Contingent negative variation and psychological processes in man. Psychol Bull 1972;77:73108.

3. Macar F, Besson M: Contingent negative variation in processes of expectancy, motor preparation and time estimation. Biol Psychol 1985;21:293-307.

4. Verleger R, Wauschkuhn B, van der Lubbe R, Jaskowski P, Trillenberg P: Posterior and anterior contribution of hand-movement preparation to late CNV. Int J Psychophysiol 2000;14:69-86.

5. Rohrbaugh JW, Gaillard AWK: Sensory and motor aspects of the contingent negative variation; in Gaillard AWK, Ritter W (eds): Tutorials in ERP's Research: Endogenous Components. Amsterdam, North Holland, 1983, pp 269-310.

6. Brunia CHM: Movement and stimulus preceding negativity. Biol Psychol 1988;26:165-178.

7. Damen EJP, Brunia CHM: Is a stimulus conveying task-relevant information a sufficient condition to elicit a stimulus-preceding negativity. Psychophysiology 1994;31:129-139.

8. Roth WT, Duncan CC, Pfefferbaum A, Timsit-Berthier M: Applications of cognitive ERPs in psychiatric patients; in McCallum WC, Zappoli R, Denoth F (eds): Cerebral Psychophysiology: Study in Event-Related Potentials (EEG suppl 38). Amsterdam, Elsevier, 1986, pp 419- 438.

9. Timsit-Berthier M, Delaunoy J, Koninckx N, Rousseau JC: Slow potential changes in psychiatry. I. Contingent negative variation. Electroencephalogr Clin Neurophysiol 1973;35:355-361.

10. Giedke H, Bolz J: Pre- and postimperative negative variation (CNV and PINV) under different conditions of controllability in depressed patients and healthy controls. Prog Brain Res 1980;54:579-582.

11. Giedke H, Hiemann H, Rein W: La modification des potentiels évoqués lents chez des déprimés sous amitriptyline et oxaprotiline. Neurophysiol Clin 1987;17:279-287.

12. Ashton H, Golding JF, Marsh VR, Thompson JW, Hassanyeh F, Tyrer SP: Cortical evoked potentials and clinical rating scales as measures of depressive illness. Psychol Med 1988;18:305-317.

13. Elton M, De Jong R, Ferstl R: The CNV in reactive depressives and normals. Biol Psychol 1980;11:288298.

14. Bolz J, Giedke H: Controllability of an aversive stimulus in depressed patients and healthy controls: A study using slow brain potentials. Biol Psychiatry 1981;16:441-452.

15. Knott VJ, Lapierre YD: Electrophysiological and behavioral correlates of psychomotor responsivity in depression. Biol Psychiatry 1987; 22:313-324.

16. Hansenne M, Pitchot W, Pinto E, Papart P, Ansseau M: Serotonergic-1A activity and contingent negative variation. Biol Psychol 2000; 52:259-265.

17. Pierson A, Partiot A, Ammar S, Dodin V, Loas G, Jouvent R, Renault B: ERP differences between anxious-impulsive and blunted-affect depressive inpatients; in Ansseau M, von Frenckell R, Frank G (eds): Biological Markers of Depression: State of the Art. Amsterdam, Elsevier, 1991, pp 121-129. 
18. Pierson A, Partiot A, Jouvent R, Bungener C, Martinerie J, Renault B, Widlocher D: Loss of control of pre-motor activation in anxious agitated and impulsive depressives. A clinical and ERP study. Prog Neuropsychopharmacol Biol Psychiatry 1994;18:1037-1050.

19. Timsit-Berthier M, Mantanus H, Ansseau M, Devoitille JM, Dal Mas A, Legros JJ: Contingent negative variation in major depressive patients; in Johnson R, Rohrbaugh JW, Parasuraman R (eds): Current Trends in Event-Related Potential Research (EEG, suppl 40). Amsterdam, Elsevier, 1987, pp 762-771.

20. Hansenne M, Pitchot W, Gonzalez Moreno A, Gonzalez Torrecilas J, Mirel J, Ansseau M: Psychophysiological correlates of suicidal behavior in depression. A preliminary study. Neuropsychobiology 1994;30:1-3.

21. Hansenne M, Pitchot W, Gonzalez Moreno A, Urcelay Zaldua I, Ansseau M: Suicidal behavior in depressive disorder: An event-related potential study. Biol Psychiatry 1996;40:116-122.

22. Ashton H, Marshall EF, Hassanyeh F, Marsh VR, Wright-Honaris A: Biological correlates of deliberate self-harm behavior: A study of electroencephalographic, biochemical and psychological variables in parasuicide. Acta Psychiatr Scand 1994;90:316-323.

23. Dincheva EG, Piperova-Dalbokova DL: Differences in contingent negative variation related to extraversion-introversion. Person Individ Diff 1982;3:447-451.

24. Werre PF: Extraversion-introversion, contingent negative variation, and arousal; in Strelau J, Eysenck HJ (eds): Personality Dimension and Arousal. New York, Plenum, 1987, pp 59- 76.

25. Were PF, Mattie H, Fortgens C, Berretty EW, Sluiter W: Interaction between extraversion and druginduced conditions as indicated by the contingent negative variation. Biol Psychol 1994;39:45-56.

26. Howard Fenwick P, Brown D, Norton R: Relationship between CNV asymmetries and individual differences in cognitive performance, personality and gender. Int J Psychophysiol 1992;13:191-197.

27. Krijns PW, Gaillard AWK, Van Heck GL, Brunia CHM: Personality effects on brain potentials in an S1-S2 paradigm. Person Individ Diff 1994;16:561-570.

28. Cloninger CR, Svrakic DM, Przybeck TR: A psychobiological model of temperament and character. Arch Gen Psychiatry 1993;50:975-990.

29. Cloninger CR, Przybeck TR, Svrakic DM, Wetzel RD: The Temperament and Character Inventory (TCI): A Guide to Its Development and Use. Center for Psychobiology of Personality. St. Louis, Washington University, 1994.

30. Mulder G: The concept and measurement of mental effort; in Hockey RJ, Gaillard AWK, Coles MHG (eds): Energetic and Human Information Processing. Dordrecht, Nijhoff, 1986, pp 175-198.

31. Kok A: Internal and external control: A two-factor model of amplitude change of event-related potentials. Acta Psychol 1990;74:203-236.

32. Birbaumer N, Elbert T, Canavan AGM, Rockstroh B: Slow potentials of the cerebral cortex and behavior. Physiol Rev 1990;70:1-41.

33. American Psychiatric Association: Diagnostic and Statistical Manual of Mental Disorders, ed 4. Washington, American Psychiatric Association, 1994.

34. Hamilton M: A rating scale of depression. J Neurol Neurosurg Psychiatry 1960;23:56-62.

35. Pélissolo A, Lépine J-P: Traduction française et premières études de validation du questionnaire de personnalité TCI. Ann Méd Psychol 1997;155:497-508. 
36. Cloninger CR, Svrakic DM: Integrative psychobiological approach to psychiatric assessment and treatment. Psychiatry 1997;60:120- 141.

37. Giedke H, Bolz J, Heimann H: Evoked potentials, expectancy wave and skin resistance in depressed patients and healthy controls. Pharmakopsychiatr Neuropsychopharmakol 1980;13:91-101.

38. Papart P, Ansseau M, Devoitille JM, Mantanus H, Timsit-Berthier M: Contingent negative variation and the severity of depression; in Stefanis CN, Soldatos CR, Rabavilazs P (eds): Psychiatry: A World Perspective. Amsterdam, Elsevier, 1991, vol 2, pp 402-408.

39. Van den Bosch RJ, Rozendaal N, Mol JMFA: Slow potential correlates of frontal function, psychosis and negative symptoms. Psychiatry Res 1988;23:201-208.

40. Oke S, Saatchi R, Allen E, Hudson NR, Jervis BW: The contingent negative variation in positive and negative types of schizophrenia. Am J Psychiatry 1994;151:432-433.

41. Hirschfeld RMA, Klerman GL, Clayton PJ, Keller MB, McDonald-Scott P, Larkin B: Assessing personality: Effects of the depressive state on trait measurement. Am J Psychiatry 1983;140:695-699.

42. Joffe RT, Regan JJ: Personality and depression. J Psychiatr Res 1988;22:279-286.

43. Reich J, Noyes R, Hirschfeld R, Coryell W, O'Gorman T: State and personality in depressed and panic patients. Am J Psychiatry 1987;144:181-187.

44. Akiskal HS, Hirschfeld R, Yerevanian B: The relationship of personality to affective disorders. Arch Gen Psychiatry 1983;40:801-810.

45. Hirschfeld RMA, Shea MT, Holzer CE: Personality dysfunction and depression; in Honing A, van Praag HM (eds): Depression: Neurobiological, Psychopathological and Therapeutic Advances. New York, Wiley, 1997, pp 327- 341.

46. Papart P, Ansseau M, Timsit-Berthier M: CNV in mood disorders; in Ogura C, Koga Y, Shimokoshi M (eds): Recent Advances in Event-Related Brain Potential Research. Amsterdam, Elsevier, 1996, pp 897900.

47. Cloninger CR: In reply (to Zuckerman, 1988). Arch Gen Psychiatry 1988;45:503-504.

48. Mulder RT, Joyce PR: Relationships of the tridimensional personality questionnaire to mood and personality measures for depressed patients. Psychol Rep 1994;75:1315-1325.

49. Zuckerman M: Sensation seeking and behavior disorders. Arch Gen Psychiatry 1988;45:502-503.

50. McCourt WF, Gurrera RJ, Cutter HSG: Sensation seeking and novelty seeking. Are they the same? J Nerv Ment Dis 1993;181:309-312.

51. Wiesbeck GA, Mauerer C, Thome J, Jacob F, Boening J: Neuroendocrine support for a relationship between 'novelty seeking' and dopaminergic function in alcohol-dependent men. Psychoneuroendocrinology 1995;20:755-761.

52. Gerra G, Zaimovic A, Timpano M, Zambelli U, Delsignore R, Brambilla F: Neuroendocrine correlates of temperament traits in humans. Psychoneuroendocrinology 2000;25:479-496.

53. Limson R, Goldman D, Roy A, Lamparski D, Ravitz B, Adinoff B, Linnoila M: Personality and cerebrospinal fluid monoamine metabolites in alcoholics and controls. Arch Gen Psychiatry 1991;48:437441.

54. Hansenne M, Ansseau M: Catecholamine function and temperament in major depressive disorder: A negative report. Psychoneuroendocrinology 1998,23:477-483. 
55. Rösler F, Manzey D, Sojka B, Stieglitz RD: Delineation of pharmacological effects by means of endogenous event-related brain potentials: An exemplification with flupentixol. Neuropsychobiology 1987;13:81-92.

56. Tecce JJ: Dopamine and VCN: Studies of drugs, disease and nutrition; in Brunia CHM, Mulder G, Verbaten MN (eds): Event-Related Brain Research (EEG suppl 42). Amsterdam, Elsevier, 1991, pp 153164.

57. Timsit-Berthier M: Contingent negative variation (CNV) in psychopharmacology; in Brunia CHM, Mulder G, Verbaten MN (eds): Event-Related Brain Research (EEG suppl 42). Amsterdam, Elsevier, 1991, pp 142-152. 